\title{
The Application Of Expert System In Diagnosing Scabies In Cattle
}

\author{
Fredrik Paulus Noach ${ }^{1}$, Sumartini Dana ${ }^{1}$, Rambu Estri Mboru Mala². \\ \{fpn@pnk.ac.id, sumartinidana@yahoo.com,rambuestri132@gmail.com\} \\ Departement of Electrical Engineering, State Polytechnic of Kupang ${ }^{1}$, Student at \\ Faculty of Veterinary Medicine Nusa Cendana University Kupang ${ }^{3}$.
}

\begin{abstract}
The process of sudden death can be experienced by cattle that are infested with scabies. This can happen if cattle which is infected with scabies are not early treated by veterinarians who understand about scabies. Therefore, in order to help breeders to diagnose the initial symptoms of scabies, this study intend to design an application of expert system that is able to diagnose scabies skin disease initially in cattle. The software works by following the works of an expert (veterinarian) in the process of diagnosing scabies skin disease. The application is built using the Tsukamoto method with Algebraic Product and uses the Intersection formula $(\cap)$ for Fuzzification process, whilest for the Defuzzification process uses the the method of Center of Gravity (COG). To test the Application is by using data taken from the sampling process in the field and those previously tested data from laboratories so that the results of the testing are expected to be able to act as a veterinarian in diagnosing scabies in cattle.
\end{abstract}

Keywords: Scabies, Expert System

\section{Background}

Scabies disease or scurvy is one of the skin diseases that are often found in cattle such as cow caused by sarcoptes scabiei mites which is characterized by itching, scabbed skin, hair loss in infected areas. At an advanced stage the skin can be stiffening and folding. According to [1] states that scabies spread easily through direct contact from those materials that are inside a cage such as fences, feedlot, and other contaminants that act as carriers. This disease causes damages such as weight loss [5], decreased meat production, skin quality and disruption to public health [3]. According to [5] mentions that untreated scabies disease can cause death of the infected cattle within approximately three months. In addition to these economic losses, this disease is also very detrimental because it is zoonotic, which is a skin disease in cattle that can spread to humans [1].

Scabies disease occurs because sarcoptes scabiei infects the host, penetrates into the layer of skin (stratum corneum). In the layer of infected skin, sarcoptes scabiei continues the life cycle after mating between males and females, the fertilized parasite can be found in the skin section of the tunnel terminal in the skin made by the parasite [2].

In accordance with the ability of the expert system which is a branch of artificial intelligence, which is able to act as an expert in a particular field of science, researchers think 
to help animal health counselors in diagnosing scabies as early as possible in cattle so those cattle farmers can avoid losses and prevent the disease transmitted to humans.

Expert system is a computer programs that imitates the reasoning of an expert with expertise in a particular area of knowledge [7]. Problems handled by an expert are not only problems that rely on the algorithm but sometimes also problems that are difficult to understand. These problems can be overcome by an expert with his knowledge and experience. Therefore an expert system is built not only based on a particular algorithm but also on the basis of science and rules. The main components of an expert system are the knowledge base and the inference engine. The knowledge base contains facts and rules, while the inference engine is the way computers process the problems as is done by an expert in their field. Many expert systems have been developed both for research and business purposes from various fields of science such as economics, finance, technology and medicine.

The disease transmission is so fast and the high mortality rate of cattle due to scabies skin disease is caused by the lack of veterinarians in remote areas so that the process of diagnosis and treatment of scabies disease is hampered. Besides the lack of veterinarians, animal health counselors in the area are also lack in-depth knowledge about the scabies disease. Therefore in this research a fuzzy rule-based Expert System Application is developed which can be used by animal health counselors in diagnosing scabies disease in cattle so that the losses of cattle farmers can be avoided.

\section{Theoretical Basis}

\section{a. Expert System}

Expert system is a computer program that is a branch of computer science called Artificial Intelligence (AI). Expert systems are knowledge-based systems, namely systems that mimic the reasoning of an expert in a particular field. This system uses human knowledge to solve problems that usually require expert expertise [7].

\section{b. Fuzzy Rule-Based Systems}

A fuzzy rule-based system consists of 3 (three) main components, namely: Fuzzification, Inference and Defuzzification as shown in Figure 1. 


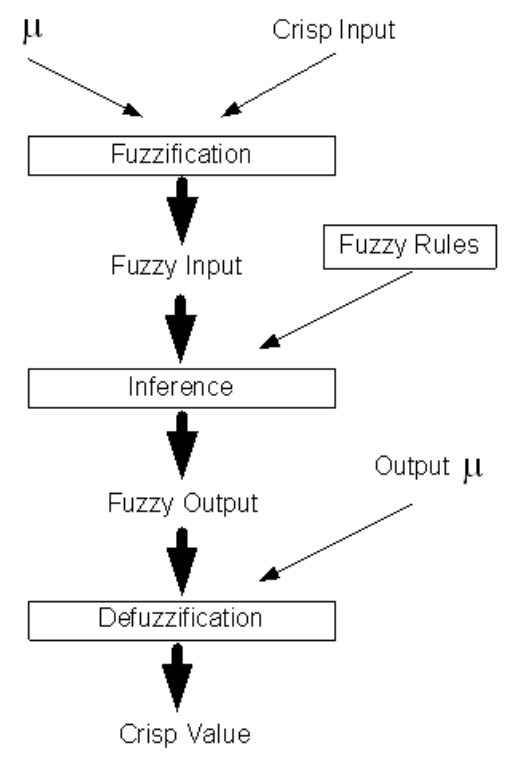

Figure 1. Diagram of Fuzzy Rule-Based System [6] and [8]

The fuzzy rules method used in this study is the Tsukamoto method. Basically, Tsukamoto's model applies monotonous reasoning to each of its rules. While monotonous reasoning, the system has only one rule, in Tsukamoto's method, the system consists of several rules. Because it uses the basic concept of monotonous reasoning, in the Tsukamoto method, each consequent to the rules in the form of IF ... THEN .... must be presented with a fuzzy set with a monotonous membership function. The output of inference results from each rule are given explicitly (crisp) based on $\alpha$-predicate (fire strength). The process of aggregation between rules is carried out, and the final result is obtained using defuzzifcation with the weighted average concept.

\section{c. Scabies Disease}

Scabies disease or more commonly known by livestock farmers as scurvy. This disease can be transmitted from infected animals to humans or zoonotic. The cause of scabies in cattle is the Sarcoptes scabie var mite. caprae. Initially, only certain body parts of the animal's body are attacked, but in severe transmission can spread throughout the whole body of the animals. The predilection organs of these mites are thin skin areas such as finger, elbow, penis, scrotum, chest, ear, and face slits [4]. Transmission of scabies spreads easily from direct contact through materials in a cage such as fences, feed containers, and other contaminants that act as carriers [1]. The symptoms of scabies disease in cattle used in this study, namely: feather loss (shed), activities to scratch the cow's body by rubbing itchy body parts into surrounding objects, and the last is a red spot on hair loss area from the cow. While the examination area is carried out on all body surfaces of a cow. 


\section{Research Methods}

There are several methods adopted in this study to yield the expected Expert System application. Those methods are Data Collection, Analysis and Design System, Implementation and System Testing.

This article explaines one form of design of the Expert System application system, namely the Design of Data Flow Diagrams (DFD) that exist in the Analysis and Design System Method. Designing Data Flow Diagrams from the Expert System application includes DFD Level 0, DFD Level 1. In Figure 2 the results of the Data Flow Diagram design show 3 (three) processes that occur in the Expert System application, namely the Input and Edit Process Data, Rule Making Process, and Diagnosis Process.

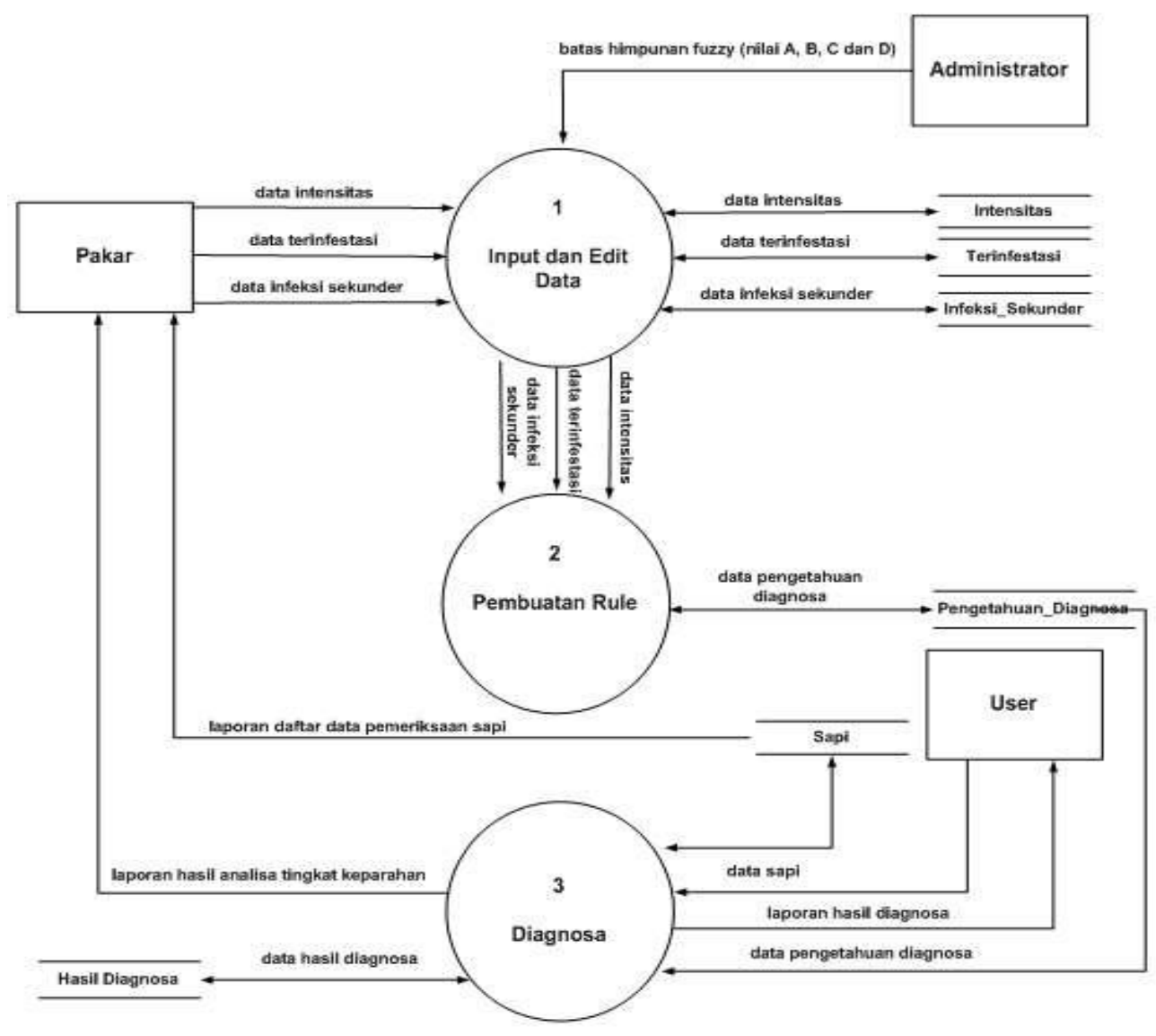

Figure 2. The Data Flow Diagram Level 1 Application of Expert System to Diagnose Scabies Disease in Cattle. 


\section{Result Of The Study}

In testing the application of Expert System diagnosis of scabies disease in cattle, secondary data is obtained from experts. These data are observations of clinical symptoms of cattle infected with scabies disease for the process of diagnosing the disease. The testing process carried out in the Expert System application is a diagnostic process to determine whether the animal has scabies or not. The process of testing the diagnosis of scabies skin disease will be carried out through a form of scabies disease diagnosis that exists in the system, as shown in Figure 3.

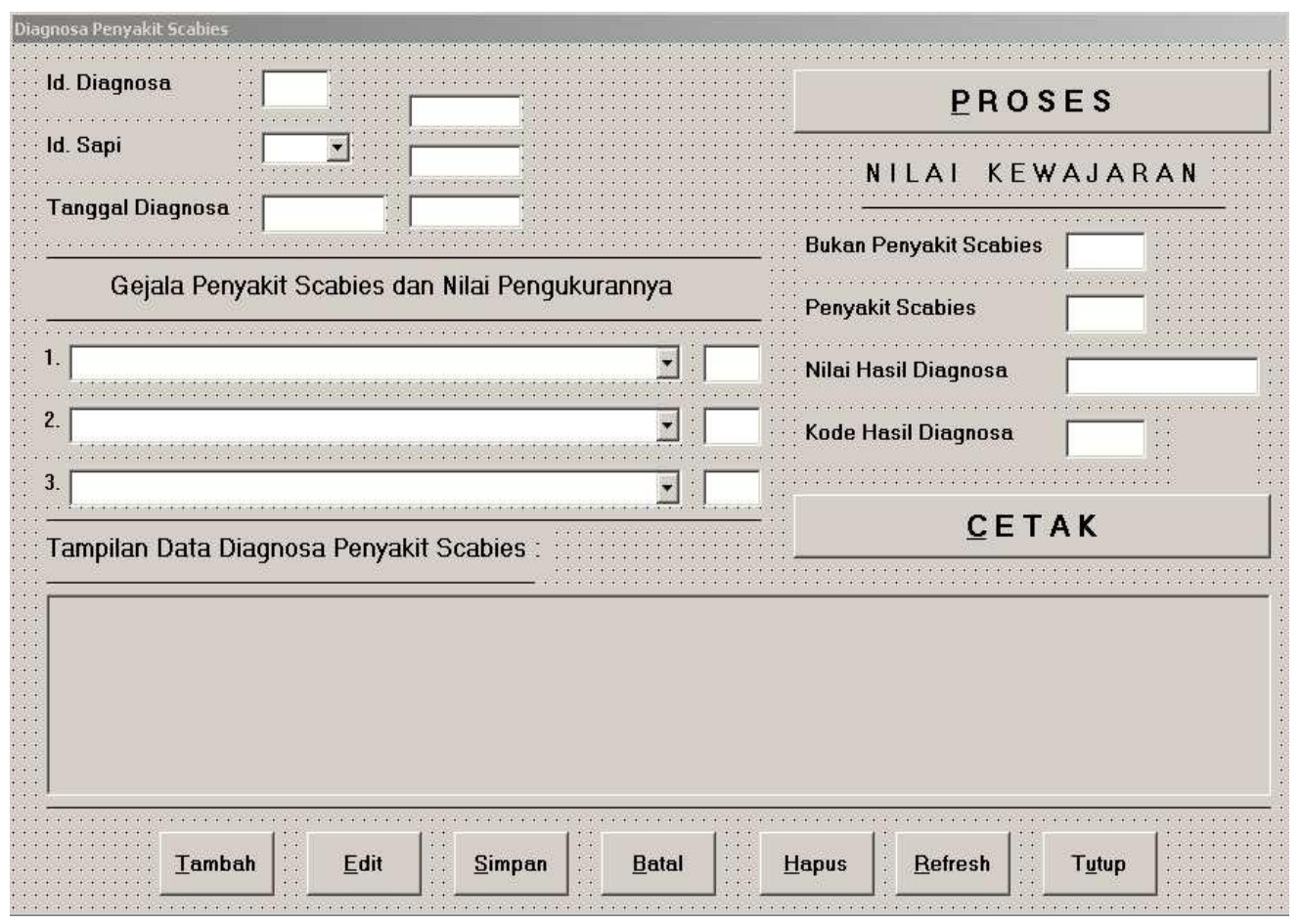

Figure 3. Scabies Disease Diagnosis Form

The process of diagnosing scabies disease in the scabies skin disease diagnosis form is divided into 3 (three) processes to produce scabies disease diagnosis results of a cow. These 3 (three) processes are:

a. Procedure for inputting data for the process of diagnosing scabies, which includes Id Diagnosis data, Id data of Cow, Date of diagnosis data, then enter the data of symptoms needed in the process of scabies disease diagnosis that is limited to each diagnostic process. Only 3 (three) symptoms of scabies disease along with measurement values (crisp values) are inputted in the form of values measurement with each unit.

b. Procedure for the diagnosis of scabies disease by pressing the "PROCESS" button. The process that occurs when pressing the button "PROCESS", namely: fuzzification Process, Inference Process, and defuzzification Process. 
c. Procedure for scabies disease diagnosis report is the process of storing scabies disease diagnosis data by pressing the "SAVE" button. Data from the process of diagnosis of scabies disease will be stored in a table. If the results of a scabies disease diagnosis are to be printed, then press the "PRINT" button to produce a diagnostic report form.

\section{Conclusions And Recommendation}

\section{a. Conclusion}

Based on the system implementation and the testing process of the Expert System application program diagnosis of scabies disease that has been done, some conclusions can be drawn as follows:

1. Knowledge-based system based on fuzzy inference using Tsukamoto method with Algebraic Product operators for the fuzzification process and Center of Gravity (COG) method for the defuzzification process used in making the Expert System application can act like an expert in the process of diagnosing the symptoms of scabies skin disease. from animals infested with scabies disease.

2. The test results using the Expert System application produce the same results with the diagnosis of scabies disease in cattle carried out by experts.

3. From the purpose of existing research, which is to develop an Expert System application that is able to diagnose scabies disease in cattle so that it can help animal health councelors in diagnosing scabies skin disease in cattle infected with scabies disease without the help of an animal health expert has been done by the Expert System application. This is indicated by the results of testing that have been carried out using secondary data available by experts.

\section{b. Recommendation}

Based on the explanation of the design and developmet of an Expert System application system that is able to diagnose scabies skin disease in cattle, there are a number of recomendations that are expected to support further system development, namely:

1. This Expert System application can be developed by adding symptoms and the rules of these symptoms in diagnosing scabies disease, so that the performance of this system can be done optimally with a greater variety of symptoms.

2. The results of a diagnosis of scabies disease in a cow that states the animal is infested with scabies disease should be a skin sample from a cow infected with scabies skin disease is also carried out laboratory tests so that the diagnostic results are really accurate.

3. For further research, the Expert System can use other methods and operators than those already used, so the results can be compared. 


\section{Bibliography}

[1].Blood, D. C., Radostits, O. M., Henderson, J. M., 1983, Veterinary Medicine, a text book of the diseases of cattle, goats and horses, sixth edition, Bailliere Tindall, London

[2].Hoedojo., 1989, Diagnosis Scabies dengan Tinta, Maj. Parasitol, Ind. 2 (3\&4)

[3].Iskandar, T., 2000, Masalah Scabies pada Hewan dan Manusia serta Penanganannya, Wartazoa, Volume 10

[4].Levine, N. D., 1994, Buku Pelajaran Parasitologi Venteriner (Terjemahan), Gadjah Mada University Press, Yogyakarta

[5].Manurung, J., Murdiati, T. B., Iskandar, T., 1992, Pengobatan Kudis pada Kambing dengan Oli, Vaselin Belerang dan Daun Ketepeng (Cassia alata L.) : Penyempurnaan Percobaan, Penyakit Hewan, Volume XXIV

[6].Suyanto., 2008, Soft Computing, Cetakan Pertama, Informatika, Bandung

[7] Turban, E., Jay, E. A., 2001, Decision Support System and Intelligent System, six edition, Prentice-Hall International, Inc., New Jersey

[8].Wang, L. X., 1997, A Course in Fuzzy System \& Control, Printice-Hall International, Inc., New Jersey

\section{Gratitude}

This research was funded by DIPA of the State Polytechnic of Kupang fiscal year of 2019. Gratefunes to the Director of State Polytechnic of Kupang and the Head of Research and Community Center (PpM) of State Polytechnic of Kupang who provided the opportunity for researchers to carry out research. 